\title{
Simposium sobre arte megalítico
}

\author{
ANA M. ${ }^{a}$ MUÑOZ AMILIBIA
}

Del 10 al 15 de septiembre de 1992, se celebró en la Universidad de Dublín el Megalithic Art Symposium organizado por los Profesores George Eogan. Elizabeth Shee Twohig, Michael Heritv, Muiris O'Sullivan y Etienne Rynne. Pude asistir gracias a una ayuda de viaje del Vicerrectorado de Investigación de la UNED y, dado el interés que puede tener para los prehistoriadores españoles, voy a resumir los temas discutidos.

Se trataba de poner al día el estado de la cuestión, después de más de diez años de la publicación en 1981 de la magnífica síntesis Megalithic Art of Western Europe de Elizabeth Shee Twohig, profesora del Departamento de Archaeología del University College de Cork, que fue precisamente la que inició el Coloquio en la sesión inaugural. Su intervención sobre Megalithic Art Studies: perspectives and prospects, puso de manifiesto las líneas de desarrollo del arte megalítico y, al mismo tiempo, sirvió de introducción a lo que iban a ser los temas principales del Coloquio: En Irlanda, los nuevos descubrimientos en los yacimientos de Knowth, en el Condado de Meath, donde G. Eogan ha distinguido hasta quince estilos, y de Knockroe, Condado de Kilkenny, estudiado por M. O'Sullivan, ha proporcionado una nueva dimensión a la visión del arte irlandés, sobre todo en lo que se refiere a ciertos paralelos con el de la Bretaña francesa, posibilitando establecer análisis del desarrollo estilístico, aunque sea difícil fechar la secuencia. En Bretaña los progresos han sido espectaculares, con el descubrimiento de menhires decorados, como temprana muestra en la secuencia escultórica, y con un sólido encuadre del desarrollo del arte bretón. En la Península Ibérica se han dado a conocer nuevos yacimientos con muestras de arte. Aunque falte una sintesis general actualizada, hay que destacar las manifestaciones pictóricas tanto en megalitos gallegos como portugueses. Es necesario reestudiar la cuestión de la relación entre el arte mobiliar y el arte de los monumentos megalíticos, to mismo que intensificar la investigación en torno a las relaciones simbólicas y el arte de las insculturas en rocas que al parecer se inician a finales del Neolítico final más bien que en la edad del Bronce, como habitual- 
mente se creía. Seria necesaria también una revisión más crítica de la naturaleza de los contactos entre las distintas áreas.

George Eogan, profesor del Departamento de Arqueología del University College de Dublín, disertó sobre Styles and Locations: Megalithic Art in its spatial setting, basándose en los últimos descubrimientos, sobre todo en el valle de Boyne. Demostró la importancia de analizar la situación de las representaciones artísticas dentro y fuera de los grandes sepulcros de corredor. En el gran monumento de Knowth (EOGAN, G., Knowth and the passage-tombs of Ireland. Thames and Hudson, Londres 1986), los grabados de las grandes losas que rodean el exterior del túmulo, representan sobre todo motivos curvilíneos, mientras que en el interior se desarrollan también otros estilos con formas rectilíneas y angulares. La concentración de temas rectilineos aparece en el corredor, coincidiendo con otros aspectos arquitectónicos en dinteles, umbrales, y determinados tipos de cubierta. Los angulares parecen ser característicos de la cámara. Eogan interpreta estas evidencias apuntando que el arte con motivos curvilíneos sería de caracter público, para ser visto y usado por todos. El rectilíneo y el angular serían mas restrictivos, sólo para los que tenían acceso al interior, sacerdotes o personajes de caracter especial. El corredor, lugar de concentración del arte rectilíneo, sería donde se desarrollarían ritos o ceremonias previas a la entrada en la cámara, donde se produciría el acto principal, quizás de “comunicación" con el mundo de ultratumba. La exposición suscitó gran interés y discusión, aportándose otros datos de interés. Así, la diferenciación de al menos tres técnicas de grabado: el piqueteado, la incisión y el grabado pulimentado por abrasión, que también parecen usarse con criterio selectivo según la localización, las superposiciones, la posible reutilización de losas..., etc.

La Dra. Jean McMann, del Departamento de Arquitectura de la Universidad de California (Berkley, USA), presentó un sugestivo estudio comparativo de las relaciones de simetría de once cámaras tumulares de Lough Crew, en el Condado de Meath, y las representaciones de círculos incisos sobre placas de hueso, cuyos fragmentos se encontraron en el Cairn $\mathrm{H}$ de Lough Crew. Se trataría de representaciones simbólicas de las estructuras megalíticas, que, precisamente por ser tardías - se trata de círculos hechos a compás típicamente celtas-, indicarían una continuidad en las tradiciones.

Frances Lynch, del University College of North Wales, se refirió a una losa decorada con una espiral, procedente de Llanberd, Merioneth, en Ardudwy, norte de Gales. El dato era especialmente interesante por proceder de una región en la que no se conocen tumbas de corredor neolíticas, aunque si las del tipo llamado Portal Tombs. A pesar de que el 
tema de la espiral puede encontrarse en contextos de la edad del Bronce, Hierro o incluso a comienzos de época cristiana, no puede descartarse que el presentado corresponda al Neolítico, a pesar de estar falto de contexto.

Muiris O'Sullivan trató sobre Knockroe: a new site with wider implications. Enseguida destacó la importancia del monumento, al que el autor ha dedicado su tesis doctoral, leida en 1988, y mas concretamente de sus manifestaciones artísticas (O'SULLIVAN, M. "Aproaches to Passage Tomb art", en Journal of the Royal Society of Antiquaries of Ireland, Dublín 1986, págs. 68-63). El yacimiento de Knockroe está cerca de New Grange. Está muy destruido, con el túmulo partido por el centro por el paso de un camino, y con sus grandes losas desplazadas o caídas in situ. El borde del túmulo, en cambio está bien conservado. El estudio del arte de Knockroe y su comparación con el de otros lugares de Irlanda y de fuera de la isla, le permite caracterizar el brillante foco artístico de las Passage Tomb irlandesas centrado en el mar de Irlanda y el valle del Boney, con estrechos paralelos en Bretaña, sobre todo en torno al golfo de Morbihan. Antes de este característico arte de los sepulcros de corredor, parece haber existido en las dos áreas un arte megalítico con tradiciones distintas. Concretamente en Irlanda, el arte prexistente al de las sepulturas de corredor, según O'Sullivan, ofrece estrechos paralelos en la Península Ibérica, sobre todo con su arte mueble: plaquitas de pizarra, ídolos falange e ídolos falo portugueses, que compara con el gran orthostato de New Grange, con decoración de oculados y líneas paralelas en zigzag y onduladas. Los motivos geométricos rectilineos entrecruzados y formando meandro los compara con las estelas de Gravinis, estudiadas por Le Roux.

Como gran parte de las losas decoradas de Knockroe están desplazadas de su lugar original, basándose en los datos aportados por el cercano monumento de New Grange trata de encuadrarlas en su lugar y significado original. A partir de la bóveda de New Grange distingue el "arte plástico" como conjunto y significado: en la superficie plana el diseño es rectilíneo en la abombada curvilíneo. Su interpretación estilística de la evolución del arte de los sepulcros de corredor en el valle del Boyne, difiere de la de Eogan, o más bien busca una orientación distinta, en parte ya iniciada por Twohig, señalando dos estilos o formas de ornamentación: El depictive style, que podriamos traducir por pictórico o descriptivo, se caracteriza por sus motivos geométricos simples, representados sin un orden compositivo y al parecer sin tener en cuenta, al distribuirlos, la forma del soporte: era el estilo vigente al comenzar a construirse las sepulturas y en ocasiones aparece oculto en la parte posterior de algunas losas, pero también en el frontal. El plastic style se adapta a las tres dimensiones de la piedra soporte, para lograr el mayor impacto visual 
posible, siempre en superficies visibles, los temas geométricos forman composiciones combinándose con otros que no lo son y se adapta a las estructuras supulcrales ya completas; la decoración depictive preexistente frecuentemente aparece dañada e incluso anulada por la aplicación de la llamada decoración plástica. A veces se combinan los dos estilos, lo que parece indicar que se trata de una evolución, del paso de un estilo a otro.

Esta dualidad no se ha podido comprobar en otros lugares de Irlanda fuera del valle del Boyne, exceptuando algunas sepulturas de la gran necrópolis de Loughcrew en el Condado de Meath. En general, el estilo depictive, el más antiguo en el valle del Boyne, es el más característico y extendido en los sepulcros de corredor irlandeses, aunque en Fourknoks, Knockroe y algún otro lugar se dé el estilo plástico, desarrollo del anterior y con localización más restringida a los territorios alrededor del mar de Irlanda.

En el valle del Boyne las dataciones de C 14 dan una cronología en torno al 2500 a.C., que calibradas estarian entre el 3250-3000 a.C. Según O'Sullivan, la transformación estilística en el arte de los sepulcros de corredor, tanto irlandeses como bretones, se produciría muy a finales del IV milenio. En el caso de la Península Ibérica sería necesario precisar mejor la cronología del arte mueble (en fechas no calibradas también en torno al 2500 a.C.) y ver si realmente es anterior a las composiciones del interior de los sepulcros.

Interesante complemento de la intervención anterior, fue la de Charles T. Le Roux, de la Universidad de Rennes, sobre L'art de Gavrinis. Contexte armoricaine et comparaisons avec I'Irlande. El dolmen de Gravinis en Morbihan, cuya excepcional decoración hace ya siglo y medio que fue dada a conocer, ha sido reexcavado por Le Roux entre 1979 y 1985 . La excavación ha demostrado que la sepultura está dentro de un cairn escalonado de tipo bretón, sobre el que se construyó un segundo túmulo hacia 4000 a.C. y cuya actividad duró uno o dos milenios. («New excavations at Gravinis" en Antiquity 59, 1985, 183-187).

Como ya había indicado en $1981 \mathrm{E}$. Shee-Twohig, las losas decoradas de Gravinis testimonian por lo menos dos fases estilísticas. La más antigua se relaciona directamente con el arte de los dólmenes de corredor armoricanos por su repertorio ("escudo", hacha, báculo...), su estilo y su técnica. Parece que las losas fueron reutilizadas, ya decoradas, procedentes de monumentos anteriores. El caso más espectacular sigue siendo la reutilización, para cubrir la cámara, de un fragmento de catorce metros, de una estela decorada con un hacha y dos bovinos. Esto permite enlazar directamente la construcción de Gravinis con la secuencia del gran megalitismo que se desarrolla en el área de Locmariaquer. 
La fase reciente comprende lo esencial de la decoración exhuberante y barroca que se ha comparado con la de New Grange. Pero más allá de la abundancia de líneas, parece que los únicos elementos comunes (cazoletas, "U", zigzags, líneas onduladas y espirales) no son los más característicos de cada uno de los dos repertorios, armoricano e irlandés. Para lo demás y para la composición general de la decoración, parece imponerse una filiación puramente armoricana, siendo los paneles más parecidos los de Lough Crew $U$ o Newgrange. A diferencia de la fase antigua, la decoración reciente de Gravinis parece haber sido ejecutada in situ y se desarrolla a partir de dos o tres metros de la entrada. El arte del valle del Boyne en cambio se manifiesta ampliamente en las losas exteriores que rodean el cairn, lo que no ocurre en Armórica. Las fechas de C. 14 calibradas indican que, el abandono de Gravinis se produce hacia el 3300-3100 antes de JC., precisamente cuando empiezan a construirse los grandes monumentos del valle del Boyne, hacia el 3100-3000 antes de JC. La proyección y comentario de diapositivas ilustró detalladamente la evolución de determinados tipos de hachas, escutiformes y corniformes, tratando de buscar su simbolismo o significado como partes de los conjuntos decorativos.

Por ausencia del Joel Lecornec, Conservador del Museo de prehistoria de Vannes, se leyó su comunicación sobre Le Petit Mont and its ornamentation. Este interesante monumento megalítico situado en Arzon (Bretaña) fue excavado por primera vez en 1865 y más tarde en 1905 por Le Rouzic, que también estudió sus losas ornamentadas. Las excavaciones desde 1979 a 1989 en el monumento megalítico de Petit Mont parecen demostrar tres fases constructivas a lo largo de un período que va del 4500 al 2500 a. C., habiéndose descubierto, en 1983, un nuevo sepulcro de corredor ricamente decorado: los orthostatos que lo componen proceden de otros monumentos, lo que, a juicio del autor, es una muestra más de que a comienzos del IV milenio se produce un fenómeno iconoclasta en el Morbihan. Sería contemporáneo de la Table des Marchands, de hacia el 3500 a. C.

March Patton y Olga Fich, del Museo de Jersey, presentaron un trabajo sobre The axe as symbol in armorican megalithic art. Señalaron cómo es uno de los motivos más importante y numeroso del arte megalítico armoricano, al mismo tiempo que, uno de los pocos que no presentan problemas de identificación, cuya representación abarca todo el período del megalitismo armoricano, del 4250 al 3000 a. C. en fechas calibradas. Su importancia simbólica estaría relacionada con su valor funcional como herramienta y como elemento de intercambio en la sociedad neolítica armoricana. 
Ofrecieron un análisis contextual de las hachas representadas en el arte megalítico armoricano: en diferentes tipos de monumentos, su localización dentro de ellos, su asociación con otros motivos, intentando establecer el desarrollo del símbolo y su uso a lo largo del tiempo, así como la relación entre hacha-simbolismo, hacha-intercambio, hacha-uso. Apuntan la posibilidad de que el hacha funcionara como simbolo-clave en el sistema ideológico de las comunidades del neolítico armoricano, uniendo la producción agrícola con la reproducción humana por referencia a los ancestros.

Jean L'Helgouac'h, de la Universidad de Nantes, abordó en su comunicación - L'art des tombes a couloir d'Armorique: problemes sociologiques: cronologie - toda la problemática de este arte, desde la perspectiva de su larga experiencia investigadora. Entre ella, los seis años de excavaciones en Locmariaquer (Morbihan): En el Grand Menhir caído, que por debajo se comprobó que estaba decorado, y en la Table des Marchands, dentro de cuyo túmulto "cairn" apareció sepultado un menhir seccionado. Estas excavaciones han aportado datos preciosos para tratar de explicar el problema de la reutilización de piedras decoradas en los sepulcros de corredor. Estas piedras reutilizadas, podrían proceder de la destrucción de tumbas más antiguas 0 de grandes estelas al aire libre. En Locmariaquer se ha comprobado que existió un alineamiento de piedras erectas de distintas dimensiones, decoradas o no, que fue aniquilado poco tiempo antes de que sus elementos se reutilizaran, en el paso del $\checkmark$ al IV milenio en pleno desarrollo del Neolítico armoricano. Estas destrucciones sistemáticas se comprueban en cierto perímetro del golfo de Morbihan y sus alrededores, pero también se da en otras regiones: en Loire-Atlantique (Dissignac), en el Finistère norte (Barnenez) o quizás incluso en las islas Anglo-Normandas (Le Déhus, Guernesey).

Estas piedras llevan a menudo imágenes de la divinidad neolítica, llamada «idolo", "bouclier» o "écusson» (aparenta la forma de un escudo de armas), o símbolos importantes relacionados con ella. Un examen profundo testimonia que estas piedras fueron talladas según un esquema antropomorfo simple, pero indiscutible, que nos conduce a las estelas antiguas de la Isla Gaignog. La integración de las piedras reutilizadas en las tumbas de corredor a veces obligaba a recortarlas, pero esto no ocurre siempre. Se puede dudar de un fenómeno de simple iconoclastia, consecuencia de un cambio dinástico, pero una destrucción de monumentos tan espectaculares como los de Locmariaquer, puede revelar una situación muy grave.

L'Helgouac'h piensa que podría tratarse de un traslado de la imagen de la divinidad del mundo de los vivos al de los muertos. Esto explicaría 
la reutilización sistemática y de forma idéntica y repetitiva en techos y losas. La divinidad acompañaría a los difuntos en su nueva morada. En este caso, se pregunta si los difuntos eran simples individuos o dignatarios poderosos, políticos o religiosos. Además, fuera de casos excepcionales como Gravinis y quizás Petit Mont III, habría que cuestionarse si existe un arte original de las tumbas de corredor: algunos grafitis de Barnenez, Gaignog, Colpo, Parc Guren o Mane Lud. Las bellas obras de la Table des Marchand, de Petit Mont II o de Penhape dependen del arte de las estelas, sin duda más espectacular.

Entre la Table des Marchands y el Gran Menhir, las excavaciones han revelado restos de poblamiento y los huecos para 15 menhires que han desaparecido. Debió de ser un gran Santuario y los constructores de la cámara funeraria aprovecharon los restos de las estelas. Habrá que pensar en la continuidad del lugar como espacio cultural, aunque en un momento dado la divinidad tenga un caracter funerario o de ultratumba, dentro de un espacio cerrado. Es posible que el Santuario anterior, aunque fuera abierto, con estelas bien visibles, tuviera el mismo caracter. No estaría de más recordar cómo en el vallle del Boyne, las estelas rodean el exterior del cairn, delimitando el lugar funerario subterráneo, lo mismo que los cromlechs $O$ las alineaciones, delimitan los lugares sacros, circulares o alargados. Y salvando las distancias, no puedo olvidar el enigmático ejemplo de Monte d'Accoddi, en Cerdeña, en que un lugar de culto de carácter megalítico, con menhires desde luego mucho menos monumentales que los bretones, se convierte a finales del Neolítico en un magnífico santuario escalonado. La diferencia está en que el "cairn" no cubre un espacio subterráneo, sino que sirve de base a un recinto exterior, aunque probablemente cerrado.

Antón A. Rodríguez Casal, de la Universidad de Santiago de Compostela, trató sobre The megalithic art in Galicia: Ten years later, mencionando los hallazgos de arte megalítico posteriores al libro de E. Shee: Grabados de Roza das Modias, Marco do Camballón, Mámoa de Braña, la losa de Poio o Gargantáns, y las pinturas de Dombate y Forno dos Mouros, a los que habría que añadir las estelas antropomorfas e ídolos sobre canto rodado de Paraxubeira, que también aparecen en Argalo, Axeitos y en el dolmen de Dombate, además de algún ejemplo de cerámica con decoración simbólica de soles.

Sin duda los resultados mas espectaculares son los de las nuevas excavaciones en el gran dolmen de Dombate, con pintura de línea roja continua en el corredor y en la cámara temas losángicos, a veces con puntos negros. Delante del corredor aparecieron 21 idolillos sobre cantos, alineados, lo mismo que en Paxubeira, donde hay también cuatro estelas 
antropomorfas. En el Forno dos Moros, aparece un enlucido blanco, y sobre él la pintura en rojo y negro con temas de líneas onduladas horizontales y en zigzag. En Roza das Modias hay un pequeño dolmen con serpentiformes verticales.

Rodríguez Casal terminó esbozando la cronología del arte megalítico gallego. La pintura y los ídolos los situó a mediados del IV milenio. Los círculos grabados en Galicia siempre están en el exterior y son de la edad del Bronce, lo mismo que las cupule o cazoletas. Hay también cistas del Bronce antiguo con grabados.

Marc Devignes, de la Universidad de Burdeos, habló sobre Aspects fondamentaux de l'art mégalithique peint iberique, señalando una cuarentena de megalitos pintados, desde algunos tholos de Los Millares a los más numerosos dólmenes del oeste, desde el alto Alentejo a Cantabria. La mayoría son dólmenes de corredor cuya cronología, no calibrada, puede remontarse al 3000 a. C. Las pinturas pueden ser monocromas y, más frecuentemente a base de rojo, blanco y negro. Suelen localizarse en la cámara, con la losa del fondo como motivo central de la composición a base de líneas onduladas o en zigzag, que también aparecen en los grabados de los dólmenes del occidente peninsular.

Aunque no asistieron los autores, se leyó una comunicación de Primitiva Bueno y Ricardo Balbín, de la Universidad de Alcalá de Henares, sobre Nuevas aportaciones al conocimiento del arte megalítico en la $\mathrm{Pe}$ nínsula lbérica: la situación de las estatuas-menhir en los dólmenes. Se refieren sobre todo a la estatua menhir o estela antropomorfa con serpentiforme del dolmen de Navalcán y a la de Guadalperal con líneas verticales, cazoletas y serpentiforme.

Tampoco asistió Miguel A. de Blas Cortina, de la Universidad de Oviedo del que se leyó una comunicación sobre Some aspects of megalithic art in the north of the Iberian Peninsula. Destaca el centenar de monumentos megalíticos ya conocidos en Asturias, Cantabria y el País vasco, pero sobre todo el dolmen de Santa Cruz (Cangas de Onís), que marca el límite noreste de cámaras megalíticas pintadas en la Península Ibérica. Dado a conocer en 1919 por Vega del Sella, actualmente se conoce mejor la decoración pictórica, que abarca una gran parte de la cámara sepulcral. A esto hay que añadir las estelas antropomorfas de Asturias y Guipuzcoa, así como cantos pintados con temas pseudooculados, en posible conexión con pequeños bloques de piedra pintados del Neolítico cántabro o con los ídolos en canto de río de Galicia y Portugal.

Vitor Oliveira Jorge, de la Universidad de Oporto, presentó su comunicación Towards a structural analysis of portuguese megalithic art, con la 
idea de plantear una nueva metodología de estudio mediante el análisis estructural de los contextos, sean monumentos megalíticos o no, en que aparecen las diferentes representaciones, y en suma acercarse a su significado y a la mentalidad e "intenciones" de sus autores. Para ello sería fundamental el estudio general de la organización de las superficies decoradas, teniendo en cuenta principios tan simples como las dimensiones de los elementos gráficos, su posición central o periférica, la relación entre elementos geométricos y figurativos, su situación en el monumento y elementos circunscritos o ausentes en el espacio.

Victor S. Gonçalves, de la Universidad de Lisboa, se refirió a Le groupe mégalithique de Reguengos de Monsaraz (Alentejo, Portugal). L'art et le sacré. Este conjunto con 134 dólmenes y 3 tholoi, estos construidos en los túmulos más antiguos de dólmenes de corredor, tiene además varias decenas de menhires aislados o formando cromlechs. El autor propone dos fases para el megalitismo de Reguengos a partir de la presencia o ausencia en los ajuares y del análisis de la decoración de las placas votivas de esquisto, grabadas con motivos geométricos y a veces antropomorfos. También presentó dos losas grabadas del dolmen 2 de Olivar de pega, en curso de excavación.

Mario Varela Gomes se refirió al Megalithic art from Southern Portugal, y concretamente al descubrimiento de nuevos menhires decorados con motivos solares y en escudo, líneas onduladas, zigzags, cayados, grabados y en relieve, en la región de Evora-Reguengos de Monsaraz. Señaló otra serie de monolitos decorados en el cromlech de Almendres (Evora) recientemente excavado. Los menhires decorados de Almendres, con temas esteliformes, corresponden a una fase tardía del monumento en el Neolítico final. En el mehir de Vale de Rodrigo (Evora) ha distinguido tres fases de decoración, una de ellas con representación solar, y está asociado a una sepultura abovedada de comienzos del Calcolítico. En este momento fueron derribados muchos menhires del Alto Alentejo, pero uno de Peridgoes (Reguengos de Monsaraz) fue integrado dentro de un curioso recinto, en cuyo centro se encontró una estructura de combustión.

Las representaciones de cayados o báculos aparecen en diversos tipos, pero las más naturalísticas son semejantes a las de arte mueble encontradas en las grandes tumbas megalíticas del Neolítico final, período en el que se les ha asociado también varias estelas.

Varela Gomes ha localizado varios menhires decorados en el Algarve, uno de ellos asociado a un túmulo con un depósito ritual. Los más antiguos se remontan al $V$ milenio, lo que indica un foco muy antiguo de megalitismo. Unos están decorados con bandas de líneas onduladas o 
cadenas de elipses cayendo verticalmente de un cinturón que rodea la parte alta del monolito. La mayoría de ellos con motivo fálico.

Jacques Tarrete de la dirección de Arqueología, del Ministerio de Cultura de París, presentó Recentes découvertes d'art mégalithique dans le Bassin Parisien, verdaderamente notables. Consisten en grabados de "divinidades" femeninas representadas por dos senos y un collar, en cada uno de los pilares de entrada a la cámara funeraria, reproduciendo una iconografía ya conocida en la zona. En una gran galería cubierta, una losa grabada con un hacha enmangada, una especie de punta de lanza y un cuadrado, con paralelos en los hipogeos del Marne.

Flemming Kaul se planteó Megalithic art in Denmark?, cosa que argumentó ampliamente. En los países nórdicos se ha discutido mucho si se puede remontar el comienzo del "rock art" a la época de construcción y primer uso de las tumbas megalíticas o simplemente hay que datarlas en la edad del Bronce. Recientemente han aparecido en Gadstrup unas piedras de pequeño tamaño con decoración de zigzags, y una línea de rombos, que recuerdan motivos Fourknoks en Irlanda y Barclodiad y Gawres, Anglesey. Pero no sólo van apareciendo cada vez más losas grabadas en conexión con megalitos, sino que es precisamente la decoración cerámica, incisa y plástica, la que mejor muestra la familiarización de los daneses con los motivos decorativos del arte megalítico irlandés, e incluso el pintado portugués o el mobiliar de la Península lbérica.

Gabriel Cooney, del Departamento de Arqueología del University College de Dublín trató Megalithic art from the outside y Richard Bradley, de la Universidad de Reading sobre The art of drawing boundaries: deposition and decoration in the Neolithic Landscape, destacando la importancia de la localización de los motivos decorativos en cada caso y en distintos contextos, desde las casas decoradas de Skara Brae a las rocas al aire libre y las decoraciones del arte mueble. Todo parece sugerir que el arte de las sepulturas de corredor irlandesas es la expresión más formal de ideas que están en el corazón de la cultura material neolítica.

Finalmente, Detlef $W$. Muller, se refirió a Pictures and symbols from stone-chambers in the Middle Neolithic of Sachsen-Anhalt (Middle Germany). Las decoraciones, símbolos y determinados signos parecen revelar su origen en el Neolítico de Europa occidental. Trata de descubrir el significado de algunos signos: el círculo y la rueda simbolizarían el sol, el peine la lluvia y los ramiformes el árbol de la vida. Todo ello podría estar relacionado con el culto a la fertilidad, sobre todo si se tiene en cuenta que en tres ocasiones se representa a la diosa del Dolmen.

Dos días de excursión nos permitieron tomar contacto directo con los principales monumentos, las passage tomb, y su arte, y sobre todo dis- 
frutar de la hospitalidad y sabias explicaciones de los profesores que nos acompañaron. En el Valle del Boyne, visitamos la necrópolis de Knowth, con 20 tumbas, la mayor con un enorme túmulo de unos 95 metros de diámetro, contiene dos tumbas de corredor situadas a lo largo de un eje Este-Oeste, con sus cabeceras juntas. El Profesor Eogan que dirige su excavación nos explicó detalladamente todo el proceso de construcción, que por hallarse el túmulo del monumento en fase de consolidación permitia mejor observar los detalles arquitectónicos. La riqueza ornamental, tanto de las losas exteriores como del interior de los corredores y cámara son extraordinarias. La gran tumba de Newgrange, mejor conocida a través de la bibliografía, no defraudó las expectativas, como tampoco los conjuntos de Dowth y Fourknocks 1, que permitieron ver distintos tipos de monumentos estilos ornamentales y ambientes paisajísticos. La visita a la colina de Tara, tan importante en la historia antigua de Irlanda, y a la gran necrópolis de Loughcrew, y posteriormente al Museo Arqueológico de Dublin, completaron la información de este interesante Symposium. 